\title{
SEGURANÇA JURÍDICA NA PROPOSTA JURISPRUDENCIALISTA
}

Danielle Osorio Santos

Danielle Osorio Santos. Bacharel em Direito pela Universidade de Fortaleza, especialista em Direito Empresarial pela Pontifícia Universidade Católica de São Paulo, Mestranda em Filosofia do Direito pela Universidade de Coimbra onde pesquisa precipuamente sobre a atividade jurisdicional. Advogada e professora.

\section{Resumo}

O pensamento jurídico tem se confrontado com a necessidade de conceber um direito seguro, seja seguro porque certo, seja seguro porque estabilizador. Pretendemos abordar a segurança jurídica, tendo como uma linha paradigmática o que o normativismo concebia como segurança e como pretendia alcançá-la, damos ênfase, à segurança jurídica visada em uma decisão judicativa, que é a proposta da concepção jurisprudencialista, granjeada através de um exercício metodológico permeado por uma racionalidade prático-normativamente orientada. Em que termos a proposta jurisprudencialista - que concebe o direito como um sistema normativamente aberto - mostra-se apta a promover a segurança através do direito, e como podemos encontrar nesse sistema jurídico a segurança do direito.

\section{Palavras-chave}

Pensamento jurídico; Proposta jurisprudencialista; Exercício metodológico; Segurança do direito; Segurança através do direito.

\section{Abstract}

The legal thought has been faced with the need to devise a safe right, safe whether because certain, whether because stabilizer. We seek to discuss legal certainty, bearing the comparative line drawn from the normativism when conceiving security and how it intended to supply it; and especially following the legal certainty offered within a judicial decision, which is the jurisprudencialist proposal, reached through a methodological exercise permeated by a rationality normative-practical oriented. In what terms the jurisprudencialist proposal - which conceives law as a normatively open system - is able to promote safety through law, and how can we find in this legal system the legal certainty. 


\section{Key words}

Legal thought; Jurisprudencialist proposal; Methodological exercise; Legal Certainty; Safety through law.

\section{Introdução}

A segurança jurídica surge nos horizontes da teoria do direito como valor de extrema importância, já desde os idos da Lei das XII Tábuas ${ }^{1}$, esse anseio por leis claras, relacionase com um dos aspectos da segurança, que nos remete à certeza da cognoscibilidade do direito (por isso mesmo, tem-se referido a esse tipo de segurança jurídica como certeza), traduzindo-se no conhecimento prévio do direito estatuído e dos efeitos jurídicos atribuídos pelo direito às condutas. É a previsibilidade dada pela lei, ao postular condutas e consequências (efeitos decorrentes da conduta enquadrados na previsão legislativa).

Essa exigência de certeza acompanha aqueles que submetidos a um Estado de Direito, em comunidades, e mesmo aqueles que em algumas situações se "preferem" as alternativas ao direito (vale ressaltar que a esses que buscam alternativas ao direito revela-se de extrema importância precisamente a segurança jurídica, com regras pré-determinadas e efeitos desejados para condutas previstas ${ }^{2}$ ).

São experiências a que o homem, sempre inserido em comunidade, vive desde que se coloca em relação. Já nos seio das famílias, e cada pequena célula comunitária, as regras que os rege são colocadas às claras, bem como as consequencias para as condutas. É o que percebemos quando a criança, em casa, faz algo errado, indesejado, e já tem, de antemáo conhecimento que alguma consequencia irá advir. No seio da sociedade, uma comunidade mais ampla e plural, essa certeza e estabilidade são mais difíceis de alcançar, mas não menos exigíveis, afinal, afinal, não seria desejável um direito que não pudesse promover esses valores a ele relacionados.

Vislumbra-se a segurança do direito como uma exigência ligada ao normativismo, e mesmo à forma como o início da modernidade assiste e exige a construção de um direito, tal como o restante dos (tidos como) ramos do saber científico, em que uma racionalidade teorética os pudesse sistematizar e conhecer. Essa era a resposta científica à exigência de certeza perante o direito, ele era totalmente dado, e poderia ser totalmente conhecido na lei ${ }^{3}$.

1 Primeira tentativa de codificação romana, no perído arcaico (por volta do século $\mathrm{V}$ ) em resposta à demanda da plebe que reclamava por regras claras. (CASTRO, 2007:84)

2 Quanto às "alternativas ao direito" quando preferidas por aqueles que num mundo globalizado concentram grandes riquezas ou poder financeiro, para nós, é especialmente a exigência de uma segurança jurídica, que se traduz em certeza, previsibilidade dos resultados, que motiva a opção por “alternativas ao direito", já que para esses no "mundo dos ricos”, a justiça é um valor não tão desejado.

3 Delimitando um pouco o leque de abordagens que fazemos dessa segurança jurídica como certeza do direito, nos limitamos a entender como KAUFMANN (2014: 282) no que tange ao imperativo 
A exigência de segurança, própria dos estados modernos, onde o homem, envolto em um pluralismo de concepçóes, culturas e relaçóes sociais exige uma certeza das "regras do jogo", certeza que o proteja contra os arbítrios do estado ${ }^{4}$ e ainda em suas relaçóes privadas (PECES-BARBA, 1995:133).

O que de sempre se revelou uma ficção (para não dizer utopia), pois conhecer todas as prescriçóes legislativas (mesmo que somente às quais se estivesse submetido) seria impossível, dada sua quantidade (pois a ânsia em prescrever - prevendo - todos os possíveis comportamentos e situaçóes da vida gera uma verdadeira inflação normativa). Ter-se-á atribuído a Goethe, mesmo que sem precisão a frase: "se devêssemos conhecer todas as leis, não mais haveria tempo para as violar", frase essa que mesmo sem confirmação, não deixa de traduzir as críticas a essa certeza imperiosa que visava o normativismo.

Assim se destaca a exigência da segurança do direito, e o pensamento moderno normativista, contentava-se em seu dualismo (metodológico), o direito era o posto na lei, e em outro momento aplicado, com recurso a técnicas lógicas de dedução e/ou subsunção, a construir uma resposta para o problema, mobilizando a lei. Onde, para o pensamento normativista, confluiria a segurança do direito.

Mas não tardou a perceber-se que o direito assim considerado era permeado de lacunas, antinomias e mais, leis injustas. O que abalaria o edifício seguro do direito considerado como um sistema jurídico constituído por um estrato apenas: o normativo, e se existiam lacunas (hipóteses não previstas nesse estrato unitário), o sistema era falho em termos de segurança.

As lacunas revelaram que o direito não é totalmente certo, pois existem exigências que a realidade prática, no desenvolvimento da história humana vão reclamar uma solução que se revelou não estar prevista na norma. As antinomias denunciaram que esse sistema jurídico é passível de ser palco de colisão de direitos que não foram anteriormente resolvidas na proposição normativa, antes se revelam agora na prática. As leis injustas, por sua vez demonstram que o problema da justiça náo foi totalmente resolvido anteriormente na solução legislativa imposta, e que agora o caso concreto instiga a que se coloque em choque a segurança e a justiça (clássico conflito que trataremos mais à frente).

Fruto ainda dessa exigência de segurança do direito, a juridicidade sempre se supriu de técnicas que pudessem extirpar a vulnerabilidade do sistema, aqui assenta-se o fundamento último de institutos como prescrição, decadência, coisa julgada, vigência, vacatio legis, notificações, para não mencionar os mecanismos de controle do poder estatal ${ }^{5}$.

de precisão, para que seja seguro, é mister haver positividade, que não se resume a previsão, mas essa previsão deve vir temperada com previsão, deve corresponder exatamente ao que se pretende ver no mundo fático.

4 Note-se que a luta dos modernos sempre foi entre indivíduo e estado.

5 Nossa abordagem pretende ser jurídica e náo política. 
Esse percurso traçado (através do normativismo, e o anseio dos modernos) por causticante que seja, força-nos a sempre reconhecermos aquele momento em que o homem colocou-se diante do direito como um objeto e tê-lo como ponto de partida na consideração de problemas atuais, pois, devemos ao pensamento moderno cientificista, o pensar sobre o direito, e precisamos recorrer a ele, sempre que nos colocamos diante de reflexóes como essas que aqui fazemos.

\subsection{A Segurança através do Direito para o Normativismo}

Enquanto a segurança do direito, no normativismo traduziu-se no seu casuísmo, a segurança através do direito assumiu feição de controle social, o direito, apresentava-se como instrumento eficaz de regulação de condutas, pacificação social, de imposição de suas soluçôes à vida social.

A superação da concepção dualista do direito, colocou-nos diante da questão que abordamos, se o direito não está inteiramente contido na lei, se nos furtamos à crença de que há dois momentos no pensamento jurídico, um de índole teórica, na conceitualização e outro na aplicação, como podemos prover a segurança jurídica, que técnicas, que meios podem provisionar o direito dessa qualidade?

Para além da incerteza do direito, também este não poderia ser tão somente um instrumento de controle social, aplicando sempre o seu direito certo, era precisamente dessa opção normativista que este via-se em conflito com a justiça. Essa era outra dicotomia que o normativismo não ousava enfrentar, tendo feito clara opção pela segurança, mesmo quando implicasse renunciar à justiça, pois

a idéia de justiça aponta para uma concepção menos espaçosa, mais delimitada do direito e os valores morais que ela integra e congrega dizem respeito à estabilidade, à paz, à segurança, ao proveito bem repartido e conseguido passo a passo. Na decodificação forte, as virtudes supremas estấo na exatidão, no cumprir coerentemente as normas, na obediência à lei tendo em visto o interesse comum. (FERRAZ JR. 2003, 354-355)

A questão que o normativismo náo logrou responder, e que nos toca aqui nessas páginas, dentro dessa amalgama de concepçóes da juridicidade, é como a realização prática do direito tem enfrentado a questáo da segurança jurídica.

O que nos interessa, não obstante a necessidade de traçarmos o caminho que acabamos de fazer, não é tanto a segurança jurídica, não obstante necessária, não pode, como já visto, ser colocada como um dogma insuperável, na medida em que o direito tendo-se revelado insuficientemente seguro (certo), não se pode eliminar a possibilidade de ser instrumento de segurança (segurança através do direito - estabilidade). 


\section{Segurança e Justiça}

Mas imputamo-nos o mister de abordar a segurança através do direito na decisão judicativa, o que pretendemos desenvolver a partir da invocação de uma segunda antinomia que se revela relacionada a esse tema, e que em alguns momentos já evidenciamos: a questão da segurança jurídica sempre esteve (tida) em conflito com a questão da justiça ${ }^{6}$. Acredita-se que ante o direito, há sempre uma opção a fazer-se: ser justo, ou garantir a segurança através dele, Como aduz o filósofo alemão no quarto dos seus cinco minutos de filosofia:

owing to human imperfection, the three values of the law - public benefit, legal certainty, and justice - are not always united harmoniously in laws, and the only recourse, then, is to weigh whether validity is to be granted even to bad, harmful, or unjust laws for the sake of legal certainty, or whether validity is to be withheld because of their injustice or social harmfulness (RADBRUCH, 2006:14)

O pensamento jurídico tem visto nesses dois valores uma relação antinômica, onde o direito precisa optar por ser ou justo ou certo. O normativismo via sua resposta orientada para a certeza, o direito, mais que justo necessitava ser seguro. Em uma inversão de valores (que influenciaram o pensamento histórico-filosófico que o impulsionou) ao abrir mão da liberdade em troca da segurança (BAUMAN, 2003: 26).

A proposta de uma concepção prático-normativa reflexivamente constitutiva do direito visa conjugar esses valores, não os concebendo em forma antinomicamente polarizadas, e que a ordem jurídica não deve optar por um, em detrimento do outro, mas que por estarem em relação dialética são perfeitamente compossíveis.

\section{A Segurança (através) do Direito na Proposta Jurisprudencialista}

A falha do modelo normativista em prover um direito certo, um direito seguro em si, acabou por desvelar a real necessidade do valor segurança jurídica, que está ligada à segurança através do direito, de forma que o pensamento jurídico passou a preocupar-se não somente com a precisão e previsibilidade, mas também com o valor estabilidade.

O direito apresenta-se na sociedade como esse auxílio que se presta a garantir uma estabilidade nas ordens humanas, sociais, morais, da vida em sociedade. $\mathrm{O}$ direito deve

6 O que náo é de todo estranho, se entendermos a exigência da justiça ligada ao princípio da igualdade e a segurança jurídica ligada ao princípio da liberdade, valores esses que estão também em relação delicada. (BOBBIO, 2000: 422).

7 Devido à imperfeição humana, os três valores do direito - utilidade público, certeza jurídica e justiça - não estão sempre unidas harmonicamente nas leis, e o único recurso, então é sopesar se a validade deve ser concedida mesmo para leis más, prejudiciais ou injustas, pelo bem da certeza legal, ou se a validade lhes deve ser retirada dada sua injustiça ou periculosidade social. (Tradução livre) 
prestar-se a ser essa fonte de segurança a promover uma pacificação social, diante de conflitos de interesses ou inseguranças produzidas por indefiniçóes que sejam necessárias superar. Todo direito deve prestar-se a isso na vida do homem em sociedade, seja quando concebe-o de forma autônoma a ela (sociedade) ou não.

A segurança através do direito, é esse equilíbrio que se busca mobilizar o direito (que investido de auctoritas) a conferir à existência humana a garantir a paz social, o equilíbrio nas relações. A segurança através do direito é alcançada, quando o indivíduo tem a seu dispor instrumentos jurídicos, e o próprio direito, à sua disposição, para fazer valer suas exigências de sentido ou justiça, para garantir-lhe equilíbrio nas relaçóes e outras tantas situaçóes da vida. Com Hart afirmamos:

se estudarmos aquilo que está de facto implicado em qualquer método de controlo social- regras de jogos e também direito - que consiste primariamente em padrôes gerais de conduta comunicados a categorias de pessoas, das quais se espera então a compreensão e a conformação com as regras, sem ulterior directiva oficial. Para que o controlo social deste tipo funcione, as regras devem satisfazer certas condições: devem ser inteligíveis e ao alcance da capacidade faz pessoas e, em geral, não devem ser retroactivas, embora excepcionalmente o possam ser. (HART, 2001 :223)

Em um exercício metodológico, orientado por uma racionalidade prático-normativa, a segurança através do direito, essa dimensão de estabilidade se encontra no estrato do sentido do direito, bem como no princípio normativo dele decorrente.

No horizonte da realização do direito recorrendo-se ao sistema jurídico tal como o concebe o jurisprudencialismo, podemos, portanto, pensar na segurança através do direito. Isso porque para o jurisprudencialismo concebe o direito intimamente ligado à prática, o direito se revela e se constitui na prática, a partir da provocação de um problema, que suscita um juízo.

É na mediação do juízo que emergem os critérios a serem mobilizados quando da realização judicativa e é justamente o sistema que fornecerá os elementos que possibilitem uma estabilidade (segurança jurídica). É no sistema que estará a segurança, mas o jurisprudencialismo não concebe o sistema como auto revelador em situação estática, ele reclama um problema que lhe exija solução para que entáo se revele e se constitua continuamente. Assim entende o mestre de Coimbra:

A intenção axiológico-normativa do direito vai logrando a sua objetiva manifestação e a sua determinação na normatividade do sistema jurídico - com a pluralidade dos seus elementos normativos, em que concorrem os princípios jurídico-normativos (os fundamentos), as normas (os critérios) e a elaboração reconstituinte da dogmática (a racionalizaçáo e institucionalização normativo-jurídicas) mas integrada numa constituenda e totalizante 
unidade intencional. Pelo que a realização do direito acaba por revelar-se com dois pólos: um no sistema (na intencionalidade normativa que o sistema jurídico vai manifestando), o outro no problema (no problema específico e do caso concreto decidendo). (NEVES, 2010a: 373)

O jurisprudencialismo nos propóe um modelo de realização do direito que rompe com o dualismo normativista ${ }^{8}$. Primeiro oferece-nos uma racionalidade prático-normativa a orientar o processo de decisão. Segundo, propóe um caminho que se faz caminhando, ou seja, um direito que se constitui à medida em que é realizado, e tudo, a partir de uma dialética entre sistema e problema, tendo neste último o seu prius metodológico.

O tipo de racionalidade implicado nessa concepção da juridicidade, que não teorética como o modelo proposto pelo normativismo, nem instrumental, como o proposto nas concepçóes funcionalistas; mas uma racionalidade prático-normativa e de fundamentação. E uma racionalidade essa orientada para a relação dialética entre sistema e problema.

O sistema jurídico aparece como sendo formado por diversos estratos (enquanto o normativismo nos oferece um sistema formado por normas legais), que entendemos serem quatro: o estrato dos princípios normativo-jurídicos, o estrato das normas, um terceiro estrato ocupado pela jurisprudência, e um quarto onde se encontra a dogmática. A esses estratos todos perpassa uma intenção axiológica fundamentante a que se reconhece como sendo o sentido do direito, ou seja, aquilo que nos faz reconhecer o direito como direito.

Não podemos deixar de falar da concepção antropológica do homem enquanto pessoa, porque é nesse intento que está orientado esse sentido do direito é essa a ordem última de validade de todo o sistema, e o ponto de onde se objetiva o princípio normativo, aquele que dá validade às suas construçôes normativas e jurisprudenciais.

O homem, no jurisprudencialismo é tomado não a partir da visão individualista do modernismo e nem na visão diluída no estrato social do funcionalismo, mas um homem concebido enquanto pessoa, a considerar a sua relação e constituição no meio em se encontra, essa concepção da juridicidade concebe o homem enquanto em relação, com valores inerentes a si, por ser homem, categoria ético-filosófica, mas que em relação na comunidade, adquire responsabilidades para com ela e com os outros homens como ele.

Existem dois estratos do sistema jurídico que estão mais diretamente ligados à segurança através do direito: o sentido do direito e o princípio normativo (NEVES, 2013: 280), sendo este "princípio normativo esse objetivado na 'consciência jurídica geral' qual seja 'a sintese de todos os valores e princípios normativos que nessa comunidade dão sentido fundamental ao direito ou que verdadeiramente lhes conferem o sentido de direito.". E no quadro da decisão judicativa, emerge com especial importância a exigência de fundamentação.

8 Referimo-nos aqui ao dualismo metodológico do normativismo. 
Emerge com destaque a dimensão axiológico-jurídica do sistema, como vimos explicitado por Neves:

Um outro nível, já essencialmente jurídico tem a ver com os valores e princípios que no nosso tempo histórico-cultural são imediatamente postulados pelo sentido último do direito, pelo sentido do direito como direito - valores e princípio já antes considerados e que agora de novo convocamos. O valor da pessoa humana e o valor relativamente autónomo da comunidade, e bem assim os princípios que decorrem da correlatividade e integrante dialética entre esses valores: o valor da dignidade humana, a implicar a personalidade ético-jurídica e o reconhecimento do homem como sujeito de direito (não mero objecto disponível), e os correlativos princípios da autonomia, da igualdade, etc., por um lado; os princípios da justiça (com as suas explicitaçôes comunitativas e distributivas), da segurança jurídica e da paz, e bem assim, da corresponsabilidade e da solidariedade comunitárias, etc., por outro lado. A síntese entre aqueles valores e estes princípios, enquanto a matriz radical e o fundamento último do sentido do direito como direito, têmo-lo designado pela comunitária consciência axiológico-jurídica. (NEVES, 2010a: 281)

Pois aí se encontram sintetizadas essas exigências de valor. Essas exigências de valor, esses princípios, vão, com o decorrer do desenvolvimento histórico, se objetivando no sistema, quer pela mediação normativa, quer pela mediação judicativa.

Da concepção do homem como pessoa acima referida decorre o princípio normativo $^{9}$, que irrompe no sistema jurídico como a exigência de validade normativa referida a esse homem. Portanto, o princípio normativo irrompe como um produto cultural humano, ligado a uma perspectiva histórico-cultural, pois em cada homem concebido dentro de um horizonte cultural específico, vai exigir um determinado conjunto de valores a dar sentido à produção cultural que dele emana e o rodeia.

É nessa objetivação da exigência de sentido (leia-se: princípio normativo ${ }^{10}$ ), que expressa valores que o homem culturalmente considerado exige, que emerge a segurança jurídica (e podemos dizer também, mesmo não sendo o objeto aqui discutido, mas que já referenciado, a justiça - e cumpre-nos fazê-lo, pois já se vão, então, resolvendo as antinomias entre os dois valores).

9 Ousamos cogitar que um dos motivos pelos quais o normativismo não conseguia oferecer um direito seguro (certo ou estável) fosse porque sequer cogitou a presença de um princípio normativo. O seu sistema encontrava seu fundamento de validade último em uma auctoritas, e isso bastava, não se buscava fundamentaçôes trans-legais..

10 É no respeito à objetivação daquela consciência jurídica geral, que os homens que se submetem a determinado sistema jurídico carregam em sua subjetividade, mas que no sistema vai sendo objetivado, o que é feito através dessa exigência de sentido que se faz a todos os estratos, e para o qual estão orientados: o princípio normativo. 


\subsection{A Segurança do Direito no Jurisprudencialismo}

Sendo uma concepção da juridicidade que concebe o direito não como um sistema fechado, com uma imanência estática e em termos descritivos completamente pré-visto, mas como um sistema aberto, de normatividade aberta, em que vai sendo conhecido à medida em que mobilizado (confrontado com problemas) e mesmo constituído a partir das próprias decisões que o revelam, o jurisprudencialismo não se furta à missão de oferecer um direito que garanta sua segurança em termos de certeza.

Náo como o propunha o normativismo, sendo um sistema normativamente fechado, mas à sua forma, ao disponibilizar não "somente" no sentido do direito a garantia de que a juridicidade sempre expressará essa consciência jurídica geral da sociedade, objetivado no princípio normativo. E se náo se basta, ainda as normas jurídicas aparecem como um estrato do sistema de objetivação da intersubjetividade desse sentido, ainda podemos convocar um outro estrato, a dogmática jurídica.

A dogmática tem uma função específica de estabilização que nos importa aqui: o estrato da dogmática jurídica. Esse estrato é responsável por traduzir ou elaborar as expressôes do direito vigentes, com seu sentido prático, a partir dos estratos do sistema (incluindo-se as produçóes jurisprudenciais que é um momento importante da constituiçáo do direito). A "função estabilizadora" da dogmática é importante para o jurisprudencialismo, na medida em que este, sendo um sistema normativamente aberto - porque poiético - encontra na dogmática essa estabilização (o que ousamos afirmar como segurança do direito).

\section{A Decisão Judicativa e a Garantia de uma Segurança através do Direito}

Como já se pode vislumbrar, a decisão alcançada através da relação entre o sistema e um caso judicando, é uma decisão que se propóe solucionar um problema através de sua aproximação com todos os estratos do sistema jurídico. Essa decisão sempre remeterá ao sistema, de forma que a segurança através do direito se coloca no momento em que esse sistema se propóe a dar uma resposta jurídica aos problemas.

A segurança que a decisão judicativa garante, porque baseada em uma racionalidade prático-normativa de fundamentação é uma segurança através do direito, isso porque o discurso prático se abstém de buscar conhecer o direito totalmente posto no sistema (e evocando RADBRUCH segurança do direito é positividade), pretende uma segurança de oferecer uma resposta correta ao problema que o instiga

Como antes referido, a segurança jurídica que vai objetivada no princípio normativo, e que é manejado a partir da dialética entre sistema e problema. O jurisprudencialismo entende a decisão fundamentada nos critérios mobilizados no sistema jurídico, dentre eles o princípio normativo e os princípios normativos. 
Mas como isso se objetiva numa decisão? Em primeiro, é necessário considerar que o sistema, por si só não oferece a solução para um problema juridicamente relevante, o juízo deve ser produzido a partir da relação dialética entre ambos. O problema (como prius metodológico) com sua intenção prático-normativa é aproximado ao sistema jurídico pela mediação do juízo.

A síntese dessa aproximação - tornada possível por meio da analogia - entre o sistema e o problema, constituirá uma decisão prático-normativamente ajustada, a partir da assimilação do último (o problema decidendo) pelo primeiro (o sistema jurídico com todos os seus estratos constituintes e sua intenção prático-normativa).

Assim, esse exercício metodológico visa exorcizar a voluntas do decidente - e sua possível subjetividade - e procura oferecer uma soluçáo que se encontre efetivamente como produzida a partir da aproximaçáo entre sistema e problema, decisão essa que necessita estar fundamentada nos critérios manejados no sistema, a decisão reconduz a uma fundamentação.

Diante da problemática da segurança, uma outra questão pode ser posta: uma decisão que mobilize o princípio normativo como fundamento, porque é indeterminado, não poderá acabar por perverter seu sentido? Uma resposta inadequada inevitavelmente abalaria a estabilidade propugnada pela segurança através do direito.

Três garantias podem ser convocadas contra esse perigo, uma intencional, uma institucional, e uma metodológico-jurídica. A garantia intencional traduz-se na consonância que deverá haver entre a decisão e o princípio normativo convocado, e essa consonância será alcançada através mesmo do processo judicial que se prontifica como um eficaz instrumento de controle da realização do princípio normativo - e essa é a garantia institucional.

A garantia metodológico-jurídica conforme fomos construindo dessas últimas páginas, é a produção de uma decisão judicativa (mobilizando uma racionalidade prática de fundamentação, a confrontar um sistema e um problema) que se refere aos seus fundamentos.

\section{A Questão das Fontes do Direito}

Uma última referência que nos importa fazer aqui (insuficientemente, reconhecemos) é que o problema da segurança jurídica, especialmente a segurança do direito, estaria ligado ao problema das fontes do direito. Conhecer o direito implica saber de onde vem o direito, para que possa ser encontrado. O normativismo intentava contornar essa exigência através de uma única fonte de direito: a norma.

Um dos sentidos de 'fonte do direito' é o de 'fonte de conhecimento', o quid por que se conhece o direito ou o locus onde ele se revela, encontra 
e oferece. Ora, sabendo nós que para o positivismo jurídico o direito é concebido como um pressuposto-dado e que o seu modo de o considerar é o de conhecimento (modo teorético), não será de estranhar que, com exclusão dos outros ou com indiferença pelo relevo que eles possam ter globalmente no problema, esse pensamento jurídico tradicional, e ainda em grande parte o nosso, se fixe nesse sentido possível, postulando-o como o sentido especificamente jurídico ou o técnico-jurídico, o sentido que seria próprio da 'ciência do direito em sentido estrito' . Quer dizer, deste modo aquele pensamento jurídico pode-se poupar ao esforço quer de esclarecer e pôr fundadamente o problema antes de prescrever a solução, quer de justificar essa sua solução prescrita perante a intenção e o conteúdo problemáticos (NEVES, 1975: 124-125)

Enquanto o normativismo apostou em uma fonte única do direito, a norma, o jurisprudencialismo propóe, como acima explicitado, uma pluralidade de fontes do direito, onde a segurança é assegurada pelo sentido do direito e o princípio normativo, que o objetiva.

\section{Conclusões}

A exigência legítima que se faz ao direito para que seja certo e estabilizador e que não implique no sacrifício da justiça é um desafio que o jurisprudencialismo pretende assumir e responder, à medida em que o direito se constrói e decide os problemas que lhes são apresentados.

Em síntese, um juízo que assume no problema o seu prius metodológico, a desafiar o sistema a mobilizar-se para realizar o direito. O decidente, assume esse encargo e a partir do problema, em relação dialética com o sistema, orientado pelo sentido do direito a ser revelado na prática, e a concepção do homem como pessoa. Essa é a segurança através do direito que o jurisprudencialismo pretende garantir.

Entendemos que quando se fala de decisão judicativa, alcançada por meio de um exercício metodonomológico orientado pela concepção jurisprudencialista do direito, em primeiro se pensa em segurança através do direito. Concluímos, mesmo em sede de um sistema normativamente aberto, ser possível também a segurança do direito. Não uma segurança do direito nos termos em que o normativismo apregoava e falhava em alcançar, mas em termos de um direito que se constrói a partir de uma exigência de sentido que está na sociedade mesmo. A segurança do direito, no jurisprudencialismo, entendo encontrarse no próprio sentido do direito, que é essa "consciência jurídica geral" de valores que perpassam todo o estrato social e exige.

Em termos diretos, o juiz, instigado pelo problema que lhe é posto, compulsa o sistema jurídico, que não é formado apenas por normas, mas normas que encontram validade 
em princípios normativos (emanados do sistema e ditos pela ordem jurisdicional), que por sua vez fundamentam a decisão, e que por sua vez se tornam linhas orientadoras ao sistema. É assim, que o direito vai sendo prudencialmente construído em uma relação.

O modelo metodológico proposto pelo jurisprudencialismo exige a produção de uma decisão fundamentada no sistema. Trata-se, na verdade, de vincular o juiz a apresentar as razóes de sua decisão e estas devem estar inscritas nos materiais mobilizados no sistema jurídico, não obstante este supostamente disponha de maior liberdade na valoração e confronto desses materiais frente ao problema. O que no fundo vai garantir a segurança jurídica, pois passa a ser um valor a ser objetivado, mobilizado e ponderado em todo o sistema, em aproximação ao problema judicando.

Para exorcizar o arbítrio a que pretensamente se invocaria aqui, o juiz está submetido à utilização de pontos cardeais orientadores da solução jurídica a ser proposta. A decisão será alcançada a partir da mobilização dos estratos componentes do sistema jurídico, e a partir de uma racionalidade própria a um esquema metodológico que deriva sempre dessa mesma concepção.

A decisão, além de fundamentada, deve estar em consonância com o sentido do direito, que exerce o papel de orientador; segundo, deve buscar os critérios de validade da normatividade jurídica expressos pelos princípios normativos encontrados no próprio sistema.

Enquanto o normativismo apostou na certeza do direito, com um sistema fechado e que por isso propunha que o direito dessa forma realizaria a sua função de pacificação social, e que os problemas de lacunas e antinomias acabaram por reclamar uma revisão desse pensamento; a proposta jurisprudencialista aposta na segurança através do direito no momento em que possibilita a que a ele se ponha o problema e se compromete com a garantia de que a resposta que lhe dará será uma resposta jurídica e não qualquer outra resposta.

Um sistema normativamente aberto e poiético, mas que referido a um princípio normativo que objetiva as exigências de sentido de um homem concebido como pessoa, é um sistema que produz uma decisão judicativa que não se furta à segurança através do direito, e nem mesmo à certeza do direito.

\section{Referências}

Adeodato, João Maurício. Filosofia do direito (uma crítica à verdade na ética e na ciência). São Paulo: Saraiva, 2007.

Bauman, Zygmunt. Comunidade: a busca por segurança no mundo atual. Rio de Janeiro: Jorge Zahar Editor, 2003. 
Bobbio, Norberto. Teoria geral da política: a filosofia política e as liçóes dos clássicos. Rio de Janeiro: Campus, 2000.

Castro, Flávia Lages de. História do direito geral e do Brasil. Rio de Janeiro: Lumen Juris, 2007.

Cunha, Paulo Ferreira da. Iniciaçáo à metodologia jurídica. Coimbra: Almedina, 2014.

Ferraz Junior, Tércio Sampaio. Introdução ao estudo do direito (técnica, decisão, dominação). São Paulo: Atlas, 2003.

Hart, Herbert. L. A. O conceito de direito. Lisboa: Fundação Calouste Gulbenkian, 2001.

Kaufmann, Arthur. Filosofia do direito. Lisboa: Fundação Calouste Gulbenkian, 2014.

Neves, A. Castanheira. As fontes do direito e o problema da positividade jurídica. Boletim da Faculdade de Direito da Universidade de Coimbra. Coimbra, v. LI, p. 115-204, 1975.

Digesta, vol. 2º. Coimbra: Coimbra Editora, 2010a (reimpressão).

Id.. Digesta, vol. 3º. Coimbra: Coimbra Editora, 2010 b (reimpressão).

Id. Metodologia Jurídica. Coimbra: Coimbra Editora, 2013 (reimpressão)

Id. O instituto dos assentos e a funçáo jurídica dos supremos tribunais. Coimbra: Coimbra Editora, 2014 (reimpressão).

Peces-Barba Martínez, Gregorio. Legal security from the point of view of the philosophy of law. Ratio Juris, Oxford, vol. 8, n. 2, 127-141, July 1995.

Radbruch, Gustav. Five minutes of Legal Philosophy (1945). Oxford Journal of Legal Studies. Oxford, v. 26, n.1, p. 13-15, 2006. 